SHORT REPORT

\title{
Estimating physical activity level: the role of domestic activities
}

\author{
P Phongsavan, D Merom, A L Marshall, A Bauman
}

J Epidemiol Community Health 2004;58:466-467. doi: 10.1136/jech.2003.012096

A ppropriate measures of physical activity are essential for determining the population prevalence of physical activity, for tracking trends over time, and for guiding intervention efforts. Physical activity measurement is characterised by the synthesis of information on the type, frequency, intensity, and duration of activity over a specified period. To date, emphasis in physical activity assessment has been on the measurement of leisure time physical activities. However, some domestic and transport related activities entail energy expenditures equivalent to moderate intensity of 3.0-6.0 METS $^{1}$ considered to be of sufficient intensity to achieve a health benefit are yet to be included in routine population level physical activity surveillance. This leads to population estimates based only on measures of leisure time physical activities.

Recent developments in research on the energy expenditure of domestic activities have highlighted the potential contributions of these activities to health. ${ }^{2}$ Given that domestic activities may be the major source of energy expenditure for certain population groups, determining their relative contribution to the total activity level is an important step to demonstrating independent health benefits of engaging in domestic activities. We conducted additional analyses of the 1998 New South Wales (NSW) state Health Survey in Australia to examine the impact of including combined measures of "vigorous household chores and gardening activities" as well as leisure time physical activities on the population estimates of health enhancing physical activity.

\section{METHODS AND RESULTS}

Of the original 16930 aged 16 years and older who were randomly sampled for a telephone interview, 16741 respondents with physical activity data were included in the analysis. ${ }^{3}$ The physical activity dimensions assessed were sessions and minutes of: walking continuously for at least 10 minutes; other moderate and vigorous intensity leisure time physical activities, and; vigorous household chores and gardening activities in the previous week. The recommended criterion of "sufficient" activity for a health benefit defined as the accumulation of at least 150 minutes over at least five sessions per week was used for analyses.

Including domestic activities increased the prevalence of "sufficient" physical activity by $12 \%$ (table 1). However, the differences between proportions attributable to the contribution domestic activities made to the overall physical activity estimates were substantially different between men and women (10.9\% compared with $13.0 \%$ ) across all age groups. In addition, both men and women aged over 30 years reported significantly more domestic activities than their younger counterparts, although women aged over 60 years were not noticeably different from those aged between 45 and 59 years.

\section{DISCUSSION}

These results highlight the important contribution "vigorous domestic activities" can make to the overall prevalence levels of adults meeting the "sufficient" physical activity criterion, particular for women. This is important, as fewer women reported "sufficient" leisure time physical activity compared with men, but when domestic activities were included the difference between men and women, while still substantial, decreased by $2.1 \%$. The current leisure time physical activity measures may be under-estimated, and when estimating total physical activity levels the consideration of domestic activities is important. Recent studies have questioned the

Table 1 Proportions of NSW adult population meeting the minimum criterion of "sufficient" activity" with vigorous domestic activities excluded and included from total physical activity, by sex (weighted) $+(n=16741)$

\begin{tabular}{|c|c|c|c|c|}
\hline & $\begin{array}{l}\text { Walking and other leisure-time } \\
\text { physical activities } \ddagger \\
\text { Number (\%) }\end{array}$ & $\begin{array}{l}\text { Household chores and gardening } \\
\text { activities included } \\
\text { Number (\%) }\end{array}$ & $\begin{array}{l}\text { Difference between } \\
\text { estimates } \\
\text { Number }(\%)\end{array}$ & $\begin{array}{l}95 \% \mathrm{Cl} \text { for difference } \\
\text { between estimates }\end{array}$ \\
\hline Total & $7786(48.8)$ & $10102(60.9)$ & $2316(12.0)$ & 11.5 to 12.5 \\
\hline Men & 3657 (53.8) & 4505 (64.7) & $848(10.9)$ & 10.4 to 11.4 \\
\hline $16-29$ years & $818(67.0)$ & 912 (73.7) & $94(6.7)$ & 6.1 to 7.3 \\
\hline $30-44$ years & $1168(50.3)$ & $1467(63.0)$ & 299 (12.7) & 11.9 to 13.4 \\
\hline $45-59$ years & $889(48.8)$ & $1106(60.6)$ & $217(11.8)$ & 11.0 to 12.5 \\
\hline $60+$ years & $782(46.7)$ & $1020(59.8)$ & 238 (13.0) & 12.2 to 13.7 \\
\hline Women & 4129 (44.1) & $5597(57.2)$ & $1468(13.0)$ & 12.5 to 13.5 \\
\hline $16-29$ years & $949(56.8)$ & $1185(66.9)$ & 236 (10.1) & 9.5 to 10.7 \\
\hline $30-44$ years & $1380(43.0)$ & 1881 (58.3) & 501 (15.2) & 14.5 to 15.9 \\
\hline $45-59$ years & $977(42.5)$ & $1334(56.5)$ & 357 (13.8) & 13.1 to 14.5 \\
\hline $60+$ years & $823(32.2)$ & $1197(44.7)$ & 374 (12.7) & 12.0 to 13.3 \\
\hline
\end{tabular}

*"Sufficient" activity ( $\geqslant 150$ minutes plus $\geqslant 5$ sessions per week); tall estimates were calculated using weighted data for sex and age to provide a representative sample to the reference population; tinclude moderate and vigorous physical activities. 
mental and physical health benefits of vigorous domestic activities. ${ }^{45}$ Consistent evidence on this is still lacking and future assessments of domestic activities in estimating total physical activity levels in the population should not, however, be dismissed given the current emphasis on promoting active lifestyles.

The potential for selection bias because of non-respondents or reporting bias in respondents either over-reporting their behaviour or actually doing relatively more domestic chores at home could not be ruled out in these analyses. Studies validating self reported measures of domestic activities together with studies determining energy expenditure associated with vigorous domestic activities that are linked to health outcomes should be carried out, to assure their usefulness in routine physical activity surveys.

\section{ACKNOWLEDGEMENTS}

We thank the NSW Health Department for permission to use data from the 1998 NSW Health Survey.

\section{Authors' affiliations}

P Phongsavan, D Merom, A Bauman, NSW Centre for Physical Activity and Health, University of NSW, Australia
A Marshall, School of Human Movement Studies, University of Queensland, Australia

Funding: none.

Conflicts of interest: none declared.

Correspondence to: Dr P Phongsavan, NSW Centre for Physical Activity and Health, Level 2, Medical Foundation Building, 94 Parramatta Road, Camperdown, NSW 2050, Australia; p.phongsavan@unsw.edu.au

Accepted for publication 9 September 2003

\section{REFERENCES}

1 Ainsworth BE, Haskell WL, Whitt MC, et al. Compendium of physical activities: an update of activity codes and MET activities. Med Sci Sports Exer 2000;32:S498-516.

2 Weller I, Corey P. The impact of excluding non-leisure energy expenditure on the relation between physical activity and mortality in women. Epidemiology 1998;9:632-5.

3 Public Health Division. Report on the 1997 and 1998 NSW Health Surveys. Sydney: NSW Health Department, 2000. http://www.health.nsw.gov.au/ public-health/nswhs/phys/phys_intro.htm (accessed 27 Jul 2003).

4 Lawlor DA, Taylor M, Bedford C, et al. Is housework good for your health? Levels of physical activity and factors associated with activity in elderly women. Results from the British women's heart health study. J Epidemiol Community Health 2002;56:473-8.

5 Mutrie N, Hannah MK, Berger U. The relationship among different modes of physical activity and non-clinical depression. J Sports Sci 2003;21:355. 